\title{
Strengthening the Chillon viaducts deck slabs with reinforced UHPFRC
}

\author{
Eugen Brühwiler, Malena Bastien-Masse \\ Ecole Polytechnique Fédérale de Lausanne, Switzerland \\ Contact: eugen.bruehwiler@epfl.ch, malena.bastien-masse@epfl.ch
}

\section{Hartmut Mühlberg}

Monod Piguet \& Associés IC SA, Lausanne, Switzerland

\section{Bernard Houriet}

GVH SA Ingénieurs civils, Tramelan, Switzerland

\author{
Blaise Fleury \\ OPAN Concept SA Ingénieurs civils, Neuchâtel, Switzerland
}

\author{
Stéphane Cuennet, Philippe Schär \\ FEDRO - Swiss Federal Roads Office, Bern, Switzerland
}

\section{Frédéric Boudry, Marco Maurer}

WALO Bertschinger SA Construction Company, Eclépens, Switzerland

\begin{abstract}
Located in Switzerland, Chillon viaducts are two parallel highway posttensioned concrete bridges built in the late 1960s. The concrete of the deck slabs of these bridges shows signs of early stages of the alkali-aggregate reaction (AAR), which will induce, in time, a decrease of the concrete strength. To insure structural safety for future traffic demands, it was decided to strengthen the slab by adding a layer of $40 \mathrm{~mm}$ of an Ultra High Performance Fiber Reinforced cement-based Composite (UHPFRC) material, reinforced with steel rebars. Strain-hardening UHPFRC, with its low permeability, is used as a waterproofing layer protecting the slabs from the water to reduce the rate of AAR. UHPFRC has excellent mechanical properties and also acts as an external tensile reinforcement for the slab, increasing its bending and shear resistance and extending the fatigue life. To investigate this increase in structural resistance, an analytical calculation is done using models previously developed based on extensive experimental campaigns. Finally, the choice of UHPFRC for strengthening was also the most efficient in terms of intervention duration and cost.
\end{abstract}

Keywords: UHPFRC; reinforced concrete; composite section; resistance; analytical model; rehabilitation; strengthening; bridge deck slab; casting method. 


\section{Introduction}

Chillon viaducts are two parallel highway reinforced concrete (RC) bridges, each carrying one direction, opened to traffic in 1969 and located on the shores of Lake Geneva near Montreux in Switzerland (Figure 1). They consist of variable height box girders built by posttensioned segmental construction with epoxy-glued joints, and spanning between $92 \mathrm{~m}$ and $104 \mathrm{~m}$ over a total length of $2120 \mathrm{~m}$.

These structures have a high cultural value and an economic importance for the region as they are the main road link between the shores of Lake Geneva and the mountainous Canton of Wallis, carrying approximately 50'000 vehicles per day [1].

In 2012, during rehabilitation works on the viaducts, early signs of the alkali-aggregate reaction (AAR) were discovered in the concrete. In later stages, this reaction could lead to the deterioration of the concrete compressive strength. This would mean an insufficient structural safety of the bridge at Ultimate Limit
State (ULS) as well as unacceptable performance under service loads.

It was thus necessary to develop a concept for rehabilitation and strengthening to: (1) slow down the rate of AAR by protecting the concrete from water ingress; and (2) increase the ultimate resistance and stiffness of the deck slab and girder in view of potentially reduced strength of the existing concrete. Such an intervention had to be cost-effective in terms of direct construction costs and user costs, and it also had to be non-invasive in order to respect the cultural value of the bridges.

The application of a layer of an Ultra High Performance Fiber Reinforced cement-based Composite (UHPFRC) material reinforced with rebars (R-UHPFRC) was quickly found to be the most efficient technique to do so. With its outstanding properties, a layer of strain-hardening UHPFRC combines waterproofing and reinforcement of the slab [2]. Moreover, casting of UHPFRC on the bridges could be done in a short time-frame, thus reducing user-costs.

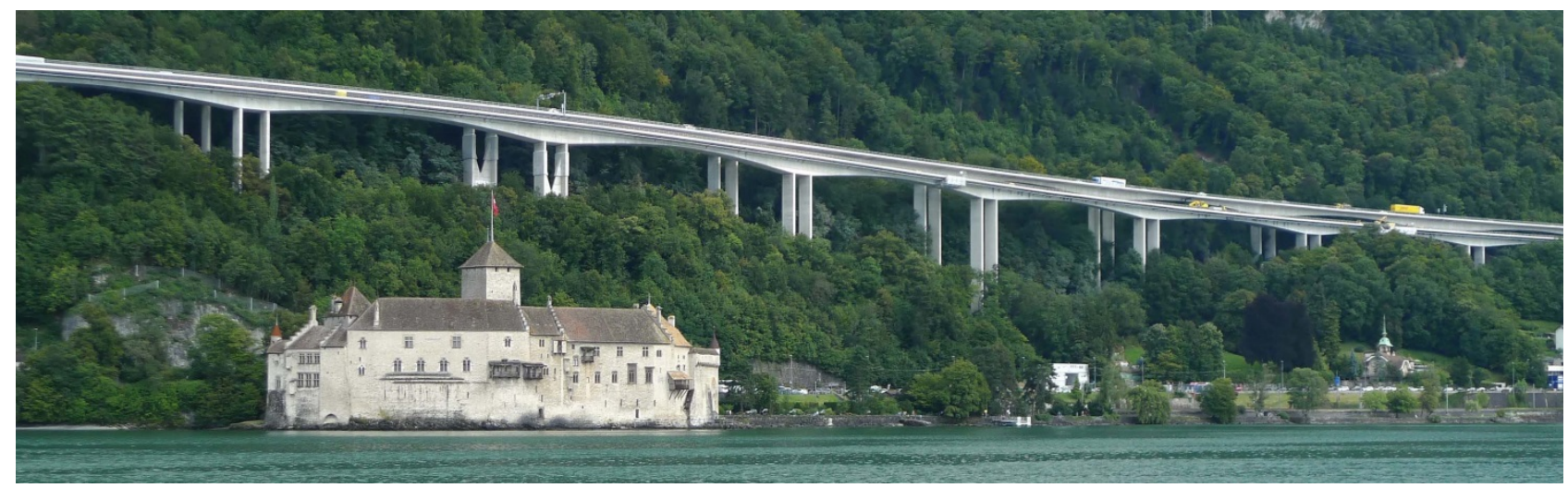

Figure 1 Chillon viaducts along Lake Geneva

\section{UHPFRC strengthening technology}

The basic concept is to use UHPFRC in the zones of a concrete structure where outstanding UHPFRC properties in terms of durability and strength are most exploited. UHPFRC is thus used to strengthen the structure where it is exposed to severe environmental conditions (de-icing salts, marine environment, etc.) and high mechanical loading (concentrated forces, fatigue, impact, etc.).

This concept is applicable both to improve and strengthen existing structures and to build new robust and durable structures. It is well suited for slabs of bridges and buildings, galleries, tunnels and retaining walls. 
The concept necessarily leads to composite structural elements combining conventional RC and UHPFRC. The protective and mechanical properties of UHPFRC combined with steel reinforcing bars (R-UHPFRC) provides a simple and efficient way of increasing the stiffness and structural resistance while keeping compact cross sections (Figure 2).

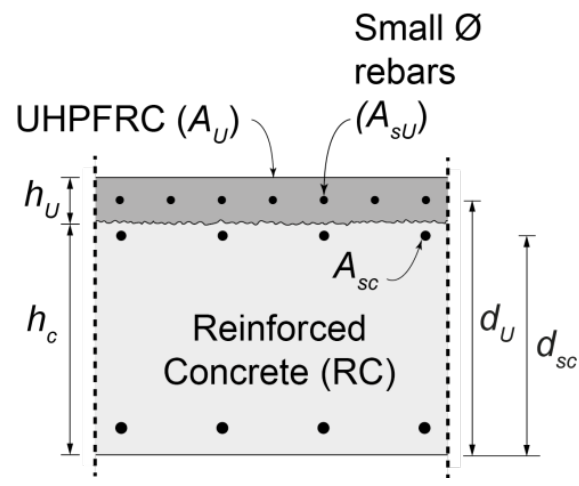

Figure 2 Typical composite cross section [5]

The original concept (developed in 1999 by the first author) has been the object of extensive research and development activities over the last 15 years in Switzerland, including numerous applications on smaller size structures [3,4]. Large experimental campaigns were carried out on full scale composite elements such as beams and slabs to characterize the properties of UHPFRC materials and the structural behaviour of $\mathrm{R}$ UHPFRC-RC composite structural members, combining material and structural engineering sciences.

Based on the results, analytical models were developed to calculate the bending, shear or fatigue resistance of a composite element. These models were used to design the UHPFRC strengthening of the Chillon viaducts as will be shown in this contribution.

\section{Conceptual design of strengthening}

The development of the AAR in the deck slabs of the viaducts was shown to be in its early stages. No surface crazing, typical of this problem, was observed on the concrete surfaces. The objective of the intervention was thus to reduce the rate of the reaction and anticipate the loss in strength of the concrete. By casting one layer of R-UHPFRC on the deck slab (with rebars in the transverse direction) of the Chillon viaducts the following beneficial effects should be achieved:

- Increase in the deck slab's ultimate resistance in the transverse direction in bending and shear;

- increase in the deck slab's stiffness to enhance the serviceability of the slab and the fatigue safety of the existing RC elements in view of future higher traffic demands in number of vehicles and axle loads;

- increase in the hogging bending moment resistance and the stiffness in the longitudinal direction of the box girder;

- provide waterproofing to protect the existing concrete of the slab from water ingress and thus limit further development of the AAR;

- limit duration and cost of the intervention by realizing all above listed requirements and structural functions by the casting of just one layer of R-UHPFRC. For this purpose, a machine was developed specifically for the casting application of the large volume of fresh UHPFRC on the 2'120 m long viaduct.

\section{Design parameters}

\subsection{Material properties}

\subsubsection{Concrete}

To take into account the future effects of AAR in the concrete when designing the UHPFRC reinforcement, a reduction of $50 \%$ of today's compressive strength was considered. The design value for the compressive strength $f_{c d}$ was thus 20 MPa.

\subsubsection{Steel}

The yield strength of the steel rebars in the existing deck slabs was taken from the construction documents. It had approximately the same value as steels commonly used today in RC. the same properties for the steel reinforcement bars in the concrete slab and in the UHPFRC layer were thus used, which is a design yield strength $f_{s d}$ of $435 \mathrm{MPa}$ and a modulus of elasticity $E_{s}$ of 205'000 MPa. 


\subsubsection{UHPFRC}

The UHPFRC layer mainly serves as an external tensile reinforcement and also increases the static height of the slab. UHPFRC tensile behaviour is characterized by an elastic phase followed by hardening and softening phases. For the design of the reinforcement, the chosen values for the elastic tensile strength $f_{\text {Uted }}$ and the tensile strength $f_{\text {utud }}$ are given in Figure 3.

When rebars are added to UHPFRC, the hardening domain reaches a strain of $2 \varepsilon_{U t u}$ or $4.0 \%$ larger than the strain at yielding of the steel rebars. Due to this compatible deformation behavior, a tension chord made of R-UHPFRC reaches its maximum resistance when steel is yielding and UHPFRC has completed its hardening phase.

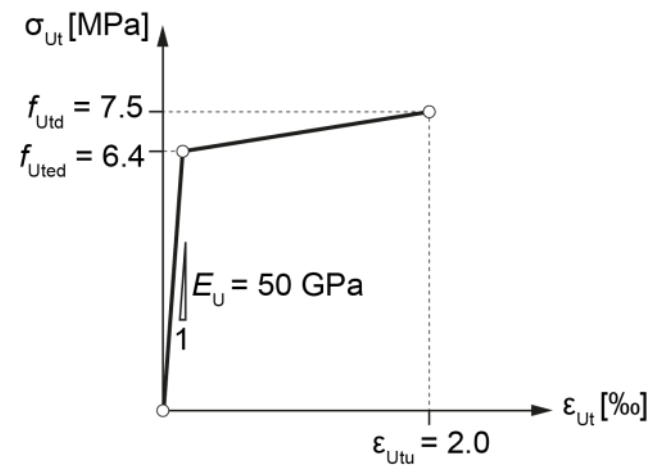

Figure 3 UHPFRC tensile hardening behavior

\subsection{Geometry}

As illustrated in Figure 4, the concrete bridge deck slab has a total thickness $h_{c}$ of $180 \mathrm{~mm}$. The transversal $16-\mathrm{mm}$ diameter top steel rebars are placed at a height $d_{s c}$ of $152 \mathrm{~mm}$ from the intrados and spaced at $125 \mathrm{~mm}$. There is no transversal prestressing in the bridge deck slab.

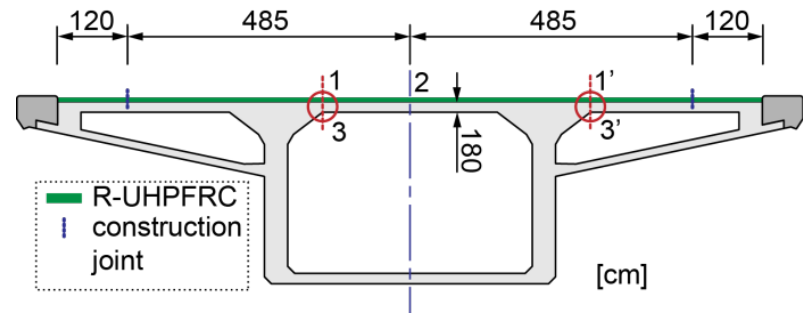

Figure 4 Geometry of the box girders cross-section

The layer of UHPFRC has a thickness of $h_{U}$ of $40 \mathrm{~mm}$ and is reinforced transversally with $12-\mathrm{mm}$ diameter rebars also spaced at $125 \mathrm{~mm}$. The center of these rebars is at $16 \mathrm{~mm}$ from the top of the concrete.

\section{Strengthening of the deck slab}

\subsection{Bending resistance at ULS}

To ensure a good connexion between the layer and the concrete substrate, the latter was prepared by high pressure water jet and wetted before UHPFRC casting. With a good surface preparation, there is experimental evidence that, in pure bending, no debonding occurs between the concrete section and the UHPFRC layer.

The composite section thus behaves monolithically up to maximum resistance [5]. The transversal bending resistance of the deck slab is thus calculated using plane-section analysis (Figure 5a for UHPFRC in tension due to negative bending moments).

(a) Bending resistance

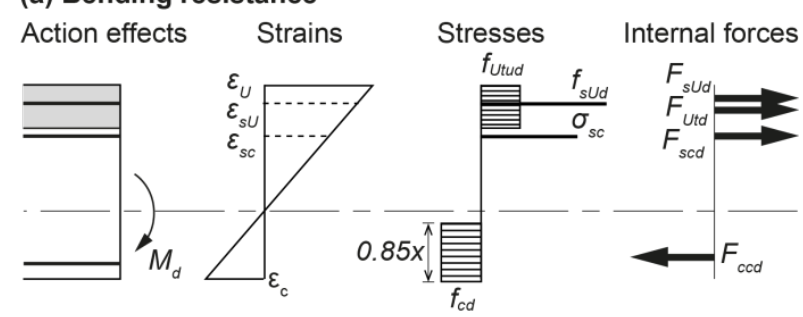

(b) Fatigue action effects

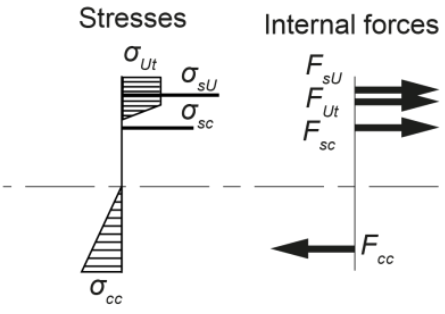

Figure 5 Plane section analysis: (a) bending resistance (adapted from [5]); (b) fatigue action effects

With this model, the maximum resistance $m_{R d}$ for sections 1 and $1^{\prime}$ (Figure 4 ) is equal to $165.5 \mathrm{kNm} / \mathrm{m}$ (considering reduced strength of the AAR affected concrete of $f_{c d}=20 \mathrm{MPa}$ ) or $73 \%$ higher than the resistance of the RC section alone (assuming today's unaffected concrete strength).

For positive bending moments, the layer of UHPFRC is in compression and mainly contributes to the resistance by reducing the height of the compression zone and thus increasing the static 
height. For the case considered here, the positive bending resistance at section 2 is increased by $33 \%$ with the new layer.

\subsection{Shear resistance at ULS}

As was shown by tests on composite beams, the addition of a layer of UHPFRC delays the formation of the inclined shear crack in the concrete section. For many geometric configurations, common UHPFRC layer thickness and steel reinforcement content, the layer of UHPFRC modifies the failure mode from shear failure with little deformation to a ductile flexural failure mode [6]. A shear failure is observed in a composite section only for very specific configurations.

The deck slab of the Chillon viaducts does not have any shear reinforcement. Shear resistance $v_{R d}$ of the composite element is thus calculated as a combination of the concrete contribution $v_{R C}$ and the UHPRRC contribution $v_{R U}$ :

$$
v_{R d}=v_{R c}+v_{R U}
$$

Concrete carries the inclined compressive stress ahead of the crack tip and fails by crushing of the compression zone. The contribution of concrete thus depends on its compressive strength $f_{c d}$ and on the angle of the inclined shear crack $\alpha_{c}$ (Fig. 6):

$$
v_{R c}=\frac{f_{c d}}{2}\left[\frac{x}{\sin \alpha_{c}} \cdot\left(1-\cos \alpha_{c}\right)\right]
$$

The widening of the inclined crack in the concrete section creates a prying action on the UHPFRC layer which resists by bending out on plane in double curvature. This is accompanied by a softening of the concrete in the concrete volume under the UHPFRC layer called Intermediate Crack induced Debonding zone (ICD). The contribution of UHPFRC to the shear resistance is thus a function of its bending resistance $m_{U}$ in double curvature over the length of the ICD zone $I_{z}$ (Figure 6) $[6,7]$ :

$$
v_{R U}=\frac{2 m_{U}}{l_{z}}
$$

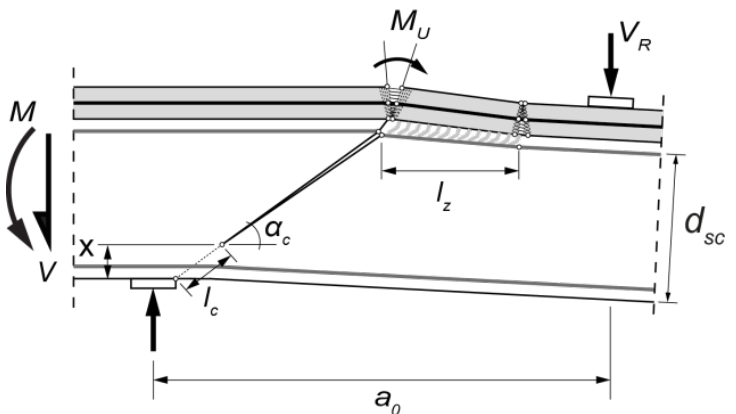

Figure 6 Shear failure mode for slab-like strips (adapted from [7])

The length of the ICD zone $I_{z}$ is estimated from the mouth of the inclined crack to the position of the concentrated load. It thus depends on the angle of the inclined shear crack $\alpha_{c}$ and the shear span $a_{0}$ :

$$
l_{z}=a_{0}-\frac{d_{s c}}{\tan \alpha_{c}}
$$

For the present slabs, the shear span $a_{0}$ corresponds to the distance between the side of the concentrated wheel load and the web of the box-girder (Figure 7). It is equal to twice the effective flexural depth $d_{\text {eff }}$ of the composite section. The effective flexural depth $d_{\text {eff }}$ is calculated with the mechanical ratio of each tensile reinforcement:

$$
d_{e f f}=\frac{\sum d_{i} A_{i} f_{i}}{\sum A_{i} f_{i}}
$$

where $i$ stands for each layer of tensile reinforcement in the composite section.
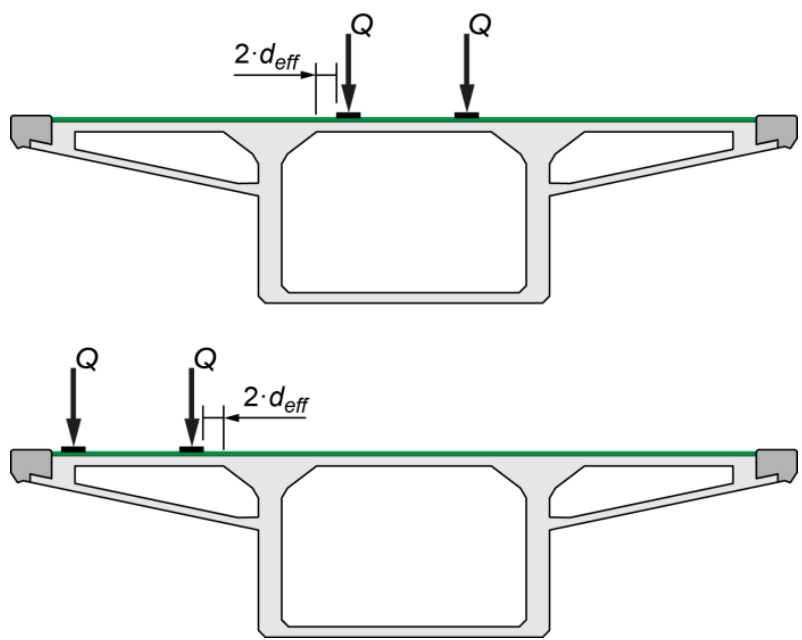

Figure 7 Position of concentrated loads for potential shear failure 
With an angle of the inclined crack estimated at $35^{\circ}$, the shear resistance of the composite section is $265 \mathrm{kN} / \mathrm{m}$. The UHPFRC layer contributes to $33 \%$ of the total shear resistance.

This shear resistance, assuming AAR affected concrete compressive strength $f_{c d}$ of $20 \mathrm{MPa}$ and as determined conservatively by considering a slab strip, is $20 \%$ higher than today's slab's shear strength (for a concentrated wheel load). As the shear resistance is significantly higher than for the flexural failure mode, the flexural failure mode is much more likely to occur also in the case of a shear prone loading situation.

\subsection{Fatigue resistance}

Based on research results, the fatigue resistance of UHPFRC, R-UHPFRC and R-UHPFRC - RC composite beams is described using a criterion referring to the fatigue endurance limit of the different materials. For the fatigue safety verification, steel reinforcing bars and UHPFRC elements should be verified in tension, while the fatigue safety of concrete needs to be verified in compression. The first goal of these verifications is to ensure that stresses in the material due to fatigue action remain below the fatigue endurance limit.

In the present case, it is supposed that stresses in the slab due to fatigue actions remain elastic according to the model given in Figure $5 \mathrm{~b}$. The RUHPFRC layer mainly contributes by reducing the level of stress in the fatigue vulnerable rebars of the concrete section below their fatigue endurance limit stress of $116 \mathrm{MPa}$ (design value according to current codes). The stress in the RUHPFRC layer is also verified. Stress in UHPFRC should stay below the following limit considering a reduction in apparent modulus of elasticity of UHPFRC in the hardening domain [8]:

$$
\Delta \sigma_{U, D}=0.3 \cdot\left(f_{\text {Uted }}+f_{U t d}\right)=4.2 \mathrm{MPa}
$$

The maximum compressive stress in the concrete due to fatigue action was calculated to be $5.6 \mathrm{MPa}$ which is below the fatigue limit of concrete in compression assumed to be $50 \%$ of $f_{c d}$ or $10 \mathrm{MPa}$ (for AAR affected concrete strength $f_{c d}$ of $20 \mathrm{MPa}$ ).

\subsection{Validation by numerical analysis and testing}

The design of the slab strengthening using RUHPFRC was validated by numerical analysis and an experimental campaign.

Non-linear Finite Element Analysis (NLFEA) were conducted to investigate the tensile stress state in the UHPFRC layer due to time-dependant effects at early age. These are due to cement hydration induced temperature, shrinkage and creep deformations. This tensile stress state is built up due to prevented deformation in the monolithic system consisting of the R-UHPFRC layer and the $\mathrm{RC}$ substrate. It shows increasing tensile stresses in the UHPFRC up to about 80 days when creep effects start to predominate and reduce these built-in stresses.

A second aim of the NLFEA was to investigate the deformation of the strengthened slab due to high wheel loads. These studies allowed to define the required tensile properties of the UHPFRC and to validate the structural behaviour of the strengthened slab.

An experimental campaign on elements representative of the Chillon viaduct slab confirmed the expected increase in ultimate resistance of the strengthened slab; the recorded structural behaviour of the elements was reproduced by NLFEA $[9,10]$.

\section{Strengthening of the box girder}

Structural analysis of the viaduct's box girder (of variable height) revealed that the arrangement and amount of existing longitudinal posttensioning was well adapted to the structural behaviour. Uniform structural safety levels were determined for all spans. However, the thickness of the compression slab close to the pier turned out to be insufficient in terms of section ductility (too high compression zone) thus limiting the plastic deformation capacity. This also explains the significant girder deformation (observed already in the past) due to creep of the spans with hinges at mid-span. It was most likely due to high compression stresses in the lower slab.

The lack of ductility had no detrimental effect on the flexural capacity of the girder and the capacity 
for moment redistribution at ULS in the hyperstatic girder system. It was anyhow decided to strengthen the lower slab of the box girder using conventional reinforced concrete. At the same time the thickness of the R-UHPFRC layer of the top slab was increased to $50 \mathrm{~mm}$ in order to incorporate steel rebars also in the longitudinal direction. This strengthening measure was applied only in the part of the girder close to the piers (extending up to one eighth of the span on each side of the piers). Taking into account the longitudinal prestressing and the added RC and UHPFRC layers, the following benefits were achieved:

- increase of flexural resistance (hogging moment capacity) of the box girder near the piers by $20 \%$;

- increase in section ductility;

- increase of girder stiffness in the longitudinal direction in anticipation of the reduced modulus of elasticity of AAR affected concrete.

\section{Construction methods}

The UHPFRC layer was cast over one 2'120 m long viaduct in less than 30 working days. The two viaducts were strengthened respectively during summers 2014 and 2015.This very fast execution was made possible by the use of a casting machine specially developed by the contractor for the placement of fresh UHPFRC (Figure 8). This machine was conceived from a paving machine. It places the UHPFRC over varying widths and levels it at the right height. Dumpers, filled at an onsite UHPFRC mixing facility, supplied regularly the machine with the fresh UHPFRC.

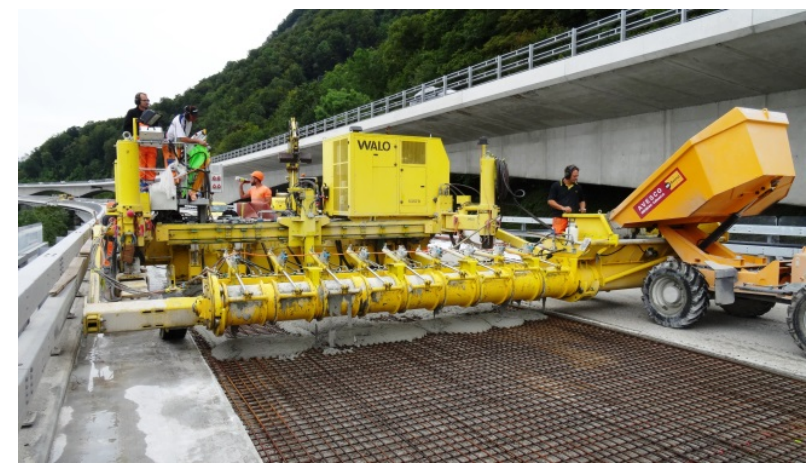

Figure 8 UHPFRC casting machine
The UHPFRC had to comply to the requirements of a strain hardening material with tensile properties as shown in Figure 2. In addition, the fresh UHPFRC had to show thixotropic behaviour as it was to be cast on slopes of up to $7 \%$. This led to a fresh UHPFRC mix with low slump flow. Although UHPFRC materials are self-compacting, in the present case, it had to be put in place by vibrating screed incorporated in the casting machine. This procedure had the advantage of leading to regular material quality while respecting the required UHPFRC layer thickness in a highly precise way. Non-destructive measurements confirmed the consistency in UHPFRC casting and revealed, as expected, a slight preferential fiber orientation in the casting direction [11].

The quality control of the UHPFRC material was conducted according to three levels: (1) initial tests confirmed the required mechanical properties; (2) compliance (suitability) tests on the construction site were conducted to adapt the UHPFRC mix and its fresh properties as well as to adjust the casting machine depending on the slopes to be cast; (3) quality tests during the execution of the UHPFRC casting according to a predefined plan. Thanks to the detailed preparation by all participants, no significant difficulty appeared during the UHPFRC casting procedure.

An asphalt layer and bituminous pavement, overall 8-cm thick, were finally placed on the UHPFRC surface to obtain the required drivable surface.

The overall cost of the intervention was $230 \mathrm{CHF} / \mathrm{m}^{2}$ which is a considerably lower than the estimated costs of conventional strengthening methods using reinforced concrete or carbon fiber lamellas. Also, the duration of the construction intervention was much shorter than for conventional technologies.

\section{Conclusions}

Strengthening of the deck slab of the AAR affected Chillon Viaducts by a layer of R-UHPFRC was the most time and cost efficient method to solve the structural problems while respecting socioeconomic constraints and important cultural values. 
With one layer of R-UHPFRC the following beneficial effects are achieved:

1. The deck slab's ultimate resistance in bending and shear is significantly increased to such a level that anticipated strength reduction of the AAR affected concrete is covered.

2. The fatigue resistance of the slab is now increased such as future higher traffic demands in number of vehicles and axle loads can be resisted.

3. The layer serves as a waterproofing protecting the concrete of the slab from water ingress and thus limiting further development of the AAR.

4. The layer also increases the resistance and stiffness of the box girder in the longitudinal direction.

Finally, with the use of a machine developed specifically for the casting of large volumes of fresh UHPFRC on the 2'120 m long viaduct, the intervention was done in a short time, limiting user costs.

As was demonstrated by the application on the Chillon viaducts, strengthening with UHPFRC is a technique suitable also for large scale structures. Many typical problems of rehabilitation projects can be solved by the smart and economic RUHPFRC strengthening method.

\section{References}

[1] Perret J, Mühlberg H, Schär P, Cuennet S. Renforcement des viaducs de Chillon. Tracés, Bulletin technique de la Suisse romande. 2014(19):7-10.

[2] Mühlberg $H$, Cuennet $S$, Brühwiler $E$, Houriet B, Boudry F, Fleury B. 2400 m3 de BFUP sur un pont autoroutier. Tracés, Bulletin technique de la Suisse romande. 2014(19):12-9.

[3] Bruhwiler E, Denarie E. Rehabilitation and Strengthening of Concrete Structures Using UltraHigh Performance Fibre Reinforced Concrete. Struct Eng Int. 2013;23(4):450-7.

[4] Bastien-Masse $M$, Brühwiler E. Ultra high performance fiber reinforced concrete for strengthening and protecting bridge deck slabs. Bridge Maintenance, Safety, Management and Life
Extension - Proceedings of the 7th International Conference of Bridge Maintenance, Safety and Management, IABMAS 2014; Shanghai: Taylor \& Francis Group; 2014, p. 2176-82.

[5] Habel K, Denarie E, Bruhwiler E. Structural Response of Elements Combining UltrahighPerformance Fiber-Reinforced Concretes and Reinforced Concrete. Journal of Structural Engineering. 2006;132(11):1793-800.

[6] Noshiravani T, Bruhwiler E. Experimental investigation on reinforced ultra-highperformance fiber-reinforced concrete composite beams subjected to combined bending and shear. ACI Struct J. 2013;110(2):251-61.

[7] Noshiravani T, Bruhwiler E. Analytical Model for Predicting Response and Flexure-Shear Resistance of Composite Beams Combining Reinforced Ultrahigh Performance FiberReinforced Concrete and Reinforced Concrete. J Struct Eng. 2014;140(6):04014012 (10 pp.).

[8] Makita T., Brühwiler E., Model for describing the fatigue behaviour of bridge deck slab elements strengthened with reinforced UHPFRC, Bridge Maintenance, Safety, Management and Life Extension - Proceedings of the 7th International Conference of Bridge Maintenance, Safety and Management, IABMAS 2014; Shanghai: Taylor \& Francis Group; 2014, pp. 2472-79.

[9] Zwicky D., Brühwiler E., Structural strengthening of the Viaducs de Chillon deck slab with reinforced UHPFRC: Full-Scale Tests, 4th Int'I Conference on Concrete Repair, Rehabilitation and Retrofitting ICCRRR2015; Leipzig; 2015.

[10] Sadouki H., Brühwiler E., Zwicky D., Chillon Viaduct deck slab strengthening using reinforced UHPFRC: Numerical simulation of full-scale tests, 4th Int'l Conference on Concrete Repair, Rehabilitation and Retrofitting; Leipzig; 2015.

[11] Nunes S, Ribeiro F, Carvalho A, Pimentel $\mathrm{M}$, Brühwiler $\mathrm{E}$, Bastien-Masse $\mathrm{M}$. Non-destructive measurements to evaluate fiber dispersion and content in UHPFRC reinforcement layers. MultiSpan Large Bridges. Porto, Portugal: CRC Press; 2015 